\title{
Effects of Inorganic Fillers on the Thermal and Mechanical Properties of Poly(lactic acid)
}

\author{
Xingxun Liu, ${ }^{1,2}$ Tongxin Wang, ${ }^{1,2}$ Laurence C. Chow, ${ }^{3}$ \\ Mingshu Yang, ${ }^{4}$ and James W. Mitchell ${ }^{2}$ \\ ${ }^{1}$ College of Dentistry, Howard University, Washington, DC 20059, USA \\ ${ }^{2}$ Crest Center for Nanomaterials, College of Engineering, Howard University, Washington, DC 20059, USA \\ ${ }^{3}$ American Dental Association Foundation, Dr. Anthony Volpe Research Center, National Institute of Standards and Technology, \\ Gaithersburg, MD 20899, USA \\ ${ }^{4}$ CAS Key Laboratory of Engineering Plastics, Institute of Chemistry, Chinese Academy of Sciences, Beijing 100190, China
}

Correspondence should be addressed to Tongxin Wang; twang@howard.edu and Mingshu Yang; yms@iccas.ac.cn

Received 11 January 2014; Accepted 1 June 2014; Published 15 July 2014

Academic Editor: Peng He

Copyright (C) 2014 Xingxun Liu et al. This is an open access article distributed under the Creative Commons Attribution License, which permits unrestricted use, distribution, and reproduction in any medium, provided the original work is properly cited.

Addition of filler to polylactic acid (PLA) may affect its crystallization behavior and mechanical properties. The effects of talc and hydroxyapatite (HA) on the thermal and mechanical properties of two types of PLA (one amorphous and one semicrystalline) have been investigated. The composites were prepared by melt blending followed by injection molding. The molecular weight, morphology, mechanical properties, and thermal properties have been characterized by gel permeation chromatography (GPC), scanning electron microscope (SEM), instron tensile tester, thermogravimetric analysis (TGA), differential scanning calorimetry (DSC), and dynamic mechanical analysis (DMA). It was found that the melting blending led to homogeneous distribution of the inorganic filler within the PLA matrix but decreased the molecular weight of PLA. Regarding the filler, addition of talc increased the crystallinity of PLA, but HA decreased the crystallinity of PLA. The tensile strength of the composites depended on the crystallinity of PLA and the interfacial properties between PLA and the filler, but both talc and HA filler increased the toughness of PLA.

\section{Introduction}

Polylactic acid (PLA)/hydroxyapatite (HA) composites have attracted great attentions for application in tissue engineering recently, because PLA and HA are both bioresorbable materials and do not need to be removed by surgery after the bone heals [1]. In comparison to PLA or HA alone, PLA/HA composites have their unique functions [2]. For example, incorporation of PLA phase into HA can improve mechanical performance as compared to HA alone. In addition, introduction of HA into PLA makes the implant more osteoconductive [1-4], and HA may have the capability to neutralize the acidic products degraded from PLA as well.

In past decades, numerous technologies have been reported on fabricating PLA/HA composites. Recently, Zhou et al. [2] have reviewed the different fabrication methods to the preparation of PLA/HA composites such as solvent casting, phase separation, electrospinning, surface coating, melt compounding, and so forth. However, most reports focused on tests on the compressive strength and the modulus. In order to be used for bone fixation, the tensile strength of PLA/CaP composites in the range of 50-150 MPa is desirable [5-7]. While the tensile strengths from most of the reported results are close to the low limit of the cortical bone [5], it is necessary to further improve the tensile strength, for example, up to $100 \mathrm{MPa}$, so that the tensile strength of the composite can best match those of natural bones from varied locations [5-7].

In order to improve the mechanical properties of PLA/ HA composites, Cui et al. [8-12] grafted polymer onto the surface of HA particles. Because polymer grafting could establish direct chemical bonding between the polymer and the filler, this strategy improved the interfacial adhesion. Further, Wang et al. [1] developed calcium-phosphate/phosphonate hybrid shell, which could introduce a greater amount of reactive hydroxyl groups onto the surface of HA particles for 
subsequent polymer grafting. Although these methods could improve the mechanical properties, there is still a distance to improve the mechanical properties, particularly the tensile strength, to the target value, for example, $100 \mathrm{MPa}$. Therefore, understanding composite fabricating condition as well as understanding the effects of the filler on mechanical and thermal properties of PLA would be necessary in order to produce PLA/HA composites with desired performance.

Annealing and orientation are two effective methods to improve the mechanical properties of PLA. Annealing could increase the crystallinity and the chain relaxation of PLA, while orientation of PLA could optimize the crystalline structure, thus increasing both of the strength and toughness [13]. Therefore, understanding the phase transition of PLA is the key to improve the mechanical properties of PLA, both from a scientific and from commercial viewpoint [13-15].

Recently, talc, namely $\mathrm{Mg}_{3} \mathrm{Si}_{4} \mathrm{O}_{10}(\mathrm{OH})_{2}$, has been used as a rigid filler and nucleation agent, in particular during annealing, to enhance crystallization of PLA, thus resulting in higher modulus, tensile strength, and crystallinity [1619]. Tsuji et al. [20] studied the effect of poly(D-lactic acid) (PDLA) as a nucleation agent on the crystallization behaviors of poly(L-lactic acid) (PLLA) and found that a small amount of PDLA was effective in accelerating the overall PLLA crystallization. By comparing the effect of talc on the phase transition of semicrystalline PLA and amorphous PLA, Yu et al. [13] found that talc enhanced the crystallization of the semicrystalline PLA significantly. Controlling the ratio of two kinds of PLA is also a good method to control the degradation of PLA $[7,18]$.

Although HA has been used as a biocompatible filler to improve the mechanical properties and biocompatibility of PLA, there are few reports on how HA affects the phase transition of PLA. In this work, two different fillers, HA and talc, were used as the model materials to illustrate how the different inorganic filler affects the thermal properties and mechanical properties of PLA during processing. A melt compounding combined with melt injection method was used to process PLA/HA composites.

\section{Materials and Methods}

The polylactic acid (PLA) with molecular weight about $100 \mathrm{KDa}$ used in this study was purchased from NatureWorks Co. (USA). The selected grade, PLA 4032 D, labeled as PLA-c, is a semicrystalline material in pellet form with an L-lactide: D-lactide ratio of $98: 2$. The glass transition temperature $\left(T_{g}\right)$ and the melting point $\left(T_{m}\right)$ are $60^{\circ} \mathrm{C}$ and $170^{\circ} \mathrm{C}$, respectively, as reported by the manufacturer. PLA4060, labeled as PLA-a, is an amorphous PLA with the D isomer monomer content from 11 to $13 \%$. Hydroxyapatite (HA) powder was purchased from Sigma-Aldrich (MO, USA). Luzenac HAR talc was supplied by Imerys Talc Company.

2.1. Preparation of PLA Based Composites. Different PLA/HA or PLA/Talc blends (see Table 1) were fabricated in Haake torque rheometer with a twin-rotary mixer (Haake Polylab System, Haake Rheomix 600, Thermo Fisher Scientific) (Scheme 1). Prior to the melt processing, PLA, talc, and HA

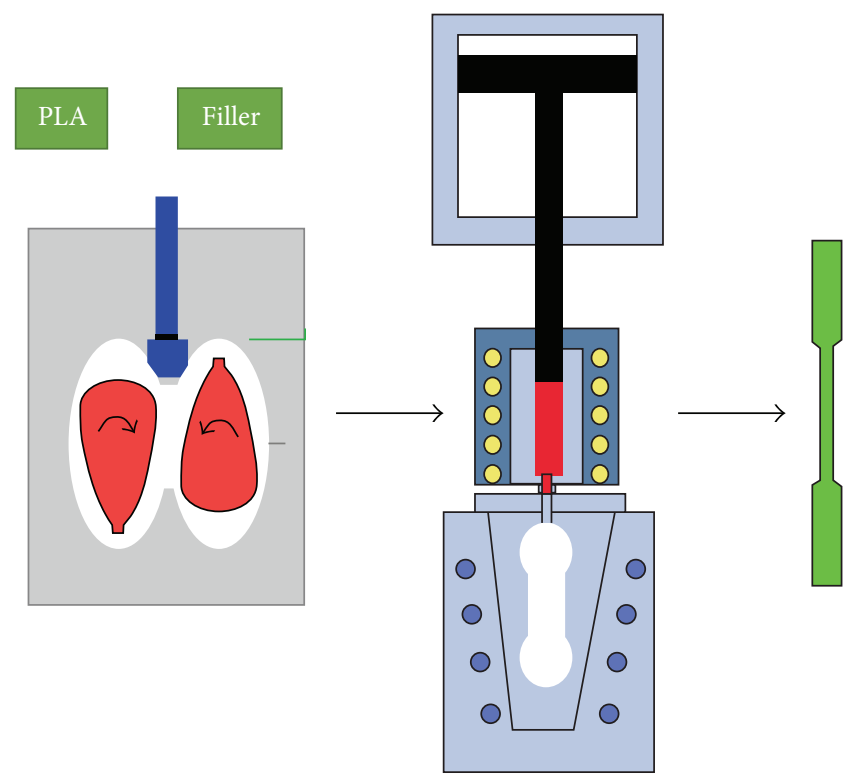

Scheme 1: Scheme for sample preparation.

TABLE 1: Sample list used for this study.

\begin{tabular}{ll}
\hline Sample code & Formulation (weight percent) \\
\hline PLA-c & PLA4032 100\% \\
PLA-a & PLA4060 100\% \\
PLA-c Ex & PLA4032 after melting mix processing \\
PLA-c/PLA-a & PLA4032 50\%/PLA4060 50\% \\
PLA-c/HA 2 & PLA 4032 98\%/HA 2\% \\
PLA-a/HA 2 & PLA 4060 98\%/HA 2\% \\
PLA-c/PLA-a/HA 2 & PLA4032 49\%/PLA4060 49\%/HA 2\% \\
PLA-c/Talc 2 & PLA 4032 98\%/Talc 2\% \\
PLA-a/Talc 2 & PLA 4060 98\%/Talc 2\% \\
PLA-c/PLA-a/Talc 2 & PLA4032 49\%/PLA4060 49\%/Talc 2\% \\
PLA-c/Talc 5 & PLA 4032 95\%/Talc 5\% \\
PLA-c/PLA-a/Talc 5 & PLA4032 47.5\%/PLA4060 47.5\%/Talc 5\% \\
\hline
\end{tabular}

were dried in the oven at $80^{\circ} \mathrm{C}$ for $4 \mathrm{~h}$. After PLA was melted at $180^{\circ} \mathrm{C}$ for $3 \mathrm{~min}$ at $80 \mathrm{RPM}, \mathrm{HA}$ or talc was added in $3 \mathrm{~min}$ at the same temperature and at 50 RPM. The blending was kept at $80 \mathrm{RPM}$ for another $5 \mathrm{~min}$. The resulting composite was subsequently molded using a piston injection molding system (Haake Minijet, Thermo Fisher Scientific). The temperature of the barrel and the mold was controlled at $210^{\circ} \mathrm{C}$ and $75^{\circ} \mathrm{C}$, respectively. All the samples were injected with an injection pressure and time of $900 \mathrm{bar}$ and $15 \mathrm{~s}$, and a postpressure and time of 350 bar and $45 \mathrm{~s}$, respectively. The injection molding tensile test specimens possessed a dog-bone shape, in accordance with ASTM 0638, type V, and DMA test specimens possessed a rectangular bar with the thickness of $3.2 \mathrm{~mm}$.

2.2. Thermogravimetric Analysis (TGA). Thermal stability was observed in terms of global mass loss by using a TA Instrument TGA Q50 thermogravimetric analyzer from 
room temperature to $800^{\circ} \mathrm{C}$ at $20^{\circ} \mathrm{C} / \mathrm{min}$. A high purity dry air stream was continuously flushed into the furnace at a flow rate of $60 \mathrm{~mL} / \mathrm{min}$ at room temperature and atmospheric pressure.

\subsection{Differential Scanning Calorimetry (DSC). A Perkin-} Elmer DSC 8000 was used to study the thermal properties at a heating rate of $10^{\circ} \mathrm{C} / \mathrm{min}$. Melting point and enthalpies of indium were used for temperature and heat capacity calibrations. Samples were cut into fine slices to improve contact with the sample pan. The crystallinity of the PLA was calculated from the fusion enthalpy of melting $\left(\Delta H_{m}\right)$, which was obtained from the DSC melting curve. The fusion enthalpy of crystallinity can be calculated from $\Delta H_{m}$ by subtracting the fusion enthalpy of melting crystallization $\left(\Delta H_{m} c\right)$. Because a previous study reported that the theoretical heat fusion of $100 \%$ crystalline PLA was $93.7 \mathrm{~J} / \mathrm{g}$ [21], the crystallinity of PLA in this work was calculated by

$$
X_{\mathrm{DSC}}=\frac{\left(\Delta H_{m}-\Delta H_{m} c\right)}{93.7} .
$$

2.4. Dynamic Mechanical Analysis (DMA). Dynamic mechanical analysis (DMA) was performed with a DMA Q800 instrument (TA Instruments) using single cantilever clamps on samples with $3.2 \mathrm{~mm}$ thickness. Samples were held horizontal by two clamps with a sample length of $17.5 \mathrm{~mm}$ between the clamps. While one clamp was fixed, the other one was applied a vertical displacement the sample. The testing specimens were subjected to a temperature ramp from -50 to $120^{\circ} \mathrm{C}$ at a rate of $2^{\circ} \mathrm{C} / \mathrm{min}$. The glass transition temperature was calculated as the mean of the loss modulus peak and the $\tan \delta$ peak.

2.5. Mechanical Test. Tensile properties of dumb-bell shaped specimens were measured in accordance with ASTM D638 using an Intron mechanical testing machine (model 5569). Tensile strength and elongation were measured at a crosshead speed of $10 \mathrm{~mm} / \mathrm{min}$.

2.6. Gel Permeation Chromatography (GPC). The test specimens were dissolved in tetrahydrofuran (THF) stabilized with $250 \mathrm{ppm}$ of 2,6-Di-terc-butil-4-metilfenol (BHT) to $3 \mathrm{mg} \mathrm{PLA} / \mathrm{mL}$ THF. The solutions were filtered using a $0.2 \mathrm{~mm}$ Teflon filter to remove the insoluble species before injecting the solute into the columns. The GPC was conducted on a PL-GPC 50 (Agilent Tech) at $1.0 \mathrm{~mL} / \mathrm{min}$ and $35^{\circ} \mathrm{C}$ calibrated with polystyrene standards. Weight-average and number-average molecular weight as well as polydispersity index were determined using the Cirrus 3.3 analysis software and the polydispersity was defined by Mw/Mn.

2.7. Scanning Electron Microscope (SEM). An Auriga Cross Beam FIB-SEM (Carl Zeiss Microscopy) was used to investigate the morphological variation of the sample. The specimens were coated with gold and viewed in the SEM by using an In-Lens detector at an accelerating voltage of $2 \mathrm{kV}$.

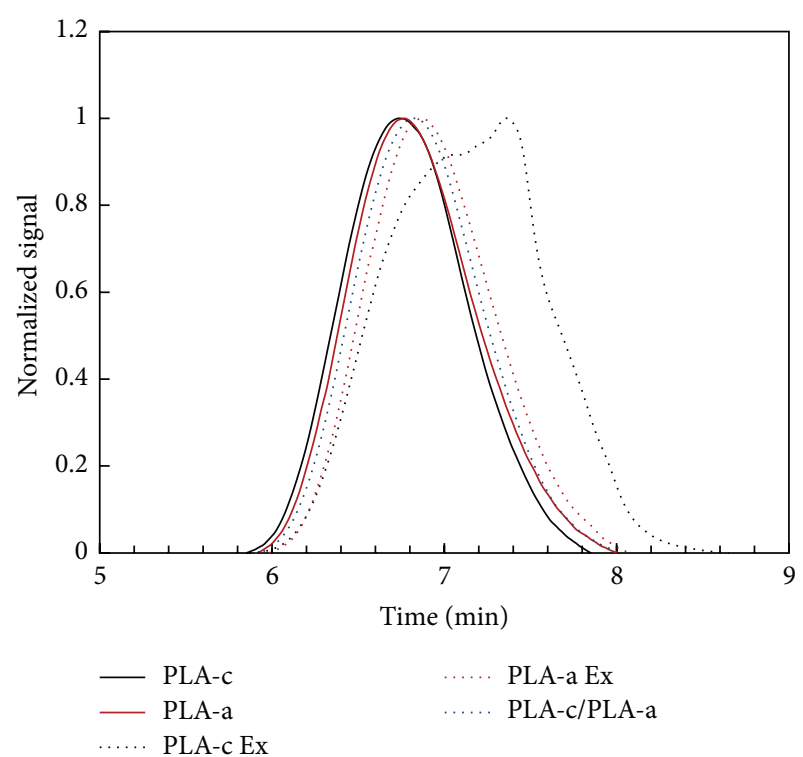

FigURE 1: GPC curves of PLA after Haake melt compounding.

\section{Result and Discussion}

3.1. Effect of Melting Mix Processing on PLA Molecular Weight and Degradation. A Haake torque rheometer (Rheomix 600) with a twin-roll mixer was used to mix the PLA and the inorganic fillers. Sample was introduced into the mixer through a top-mounted loading hopper. The torque and temperature were recorded immediately after loading. The melting and degradation behavior of PLA as well as the influences from different fillers were quantified through monitoring the torque curving, which provided useful information to optimize the mixing conditions [22].

Because PLA could be degraded due to the high temperature from such a melting process, the melting process should have impact on the mechanical strength. First, the effect of melt compounding on the molecular weight of PLA and the distribution of inorganic filler within PLA were investigated. Figure 1 shows the GPC curves of PLA after Haake mixer processing, which imposed the shear on PLA (named PLAEx). The increase of the retention time of PLA subjected to the shear indicated that the melting compounding process could cause the decrease of PLA molecular weight. The number-average molecular weight $(\mathrm{Mn})$ and weight-average molecular weight $(\mathrm{Mw})$ of the semicrystalline PLA (PLA 4032)-Ex decreased to 49,000 and 110,000, respectively, while those for the origin of PLA4032 are Mn 110,000 and Mw 190,000, respectively. The Mn and Mw of amorphous PLA (PLA 4060) also slightly decreased, but the decrease is less than the semicrystalline PLA 4032. The presence of degradation products within the melting mixture confirmed that such melting process could degrade the PLA and thus may have a negative impact on the mechanical properties of PLA, as well as the PLA/filler composite.

TGA has been used widely to study the thermal stability and decomposition of PLA and PLA based materials and to determine the amount of inorganic filler [23-25]. Figure 2 


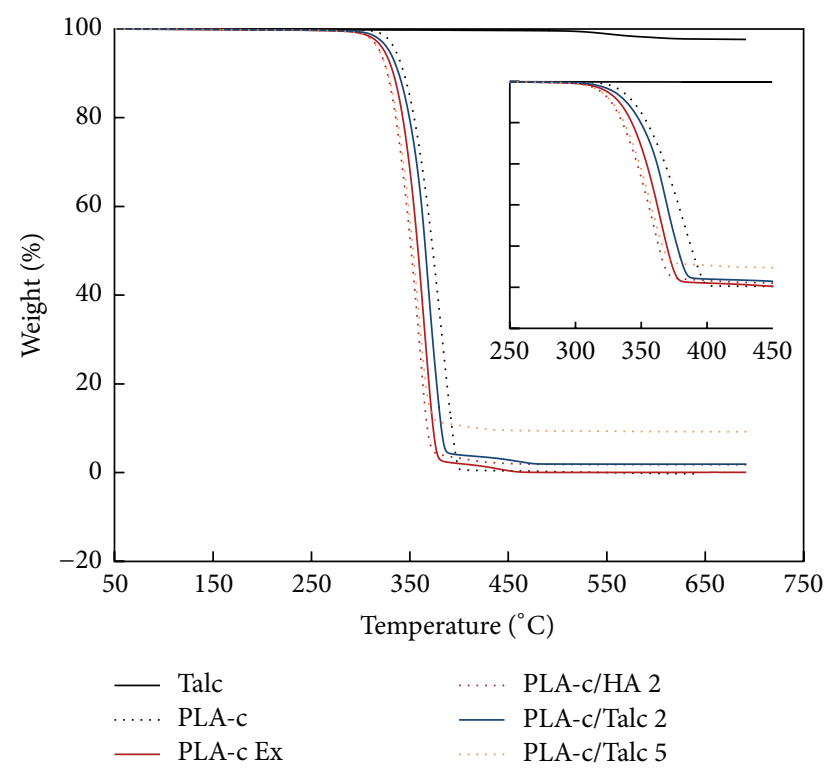

FIGURE 2: TGA results of PLA/HA and PLA/talc composites.

shows the thermal degradation of PLA and different inorganic filler composition. It is shown that the onset degradation temperature decreased after adding inorganic filler and mixing process. This may be due to the decrement of molecular weight during mixing. In addition, the content of filler within the randomly selected composites was closed to the origin formulation. This implied that the distribution of the inorganic filler within the PLA matrix was pretty homogeneous.

SEM in Figure 3 shows additional information about the distribution of inorganic filler in PLA matrix. It is shown that the HA is sphere, while the talc has lamellar structure. The aggregation of HA was also observed in Figure 3(b). However, the distribution of inorganic was homogeneous through mix processing. The voids adjacent to HA particles suggested that the interface between PLA and HA filler needed to be improved, because the voids may lead to early failure of the composite, thus limiting the mechanical properties of PLA based materials. Consequently, while melt compounding generated a good distribution of the inorganic filler in the PLA matrix, the degradation of PLA was another concern for mechanical improvement.

\subsection{Effect of Fillers on Thermal Behavior of PLA/HA Com-} posite. DSC is a useful tool to observe the phase transition of PLA, such as glass transition, melting, and cold crystallization. The DSC thermograms of semicrystaline PLA obtained for the cooling rate of $10^{\circ} \mathrm{C} / \mathrm{min}$ with various compositions are shown in Figure 4. As expected, the pure PLA-c granule exhibited neither crystallization peak upon cooling, nor significant crystallization endotherm upon heating [16]. Figure 4 also shows the DSC thermograms of PLA composites containing either HA or talc. In the presence of talc, a sharper crystallization peak was observed upon cooling. The peak occurred at $110^{\circ} \mathrm{C}$ with $5 \%$ talc loading, which was higher than that from $2 \%$ talc. However, no crystallization peak was observed in the first heating. This indicated that the PLA was already crystallized to its maximum during the cooling cycle of sample preparation. In comparison to talc, there is little effect from HA on PLA cold crystallization. The broad and large crystallization peak upon heating from HA indicated that HA may not be used to accelerate the PLA crystallization. Similar phenomenon has been also observed from other calcium salt [16].

In comparison to PLA alone, the PLA subjected to shear from melt compounding shows a different DSC profile in the heating curve, implying some molecules degraded by shear processing. Figure 4 also shows the melting and crystallization curves of DSC of the PLA/filler composites. With consideration of the melting enthalpy of $100 \%$ crystalline PLA as $93.7 \mathrm{~J} / \mathrm{g}$ [21], the crystallinity was calculated according to the formula in the Section 2.3. The crystallinity for PLA/filler composite was calculated as $35.0 \%$ (PLA-c), $12.5 \%$ (PLA-c Ex), 8.7\% (PLA-c/HA 2), 36.5\% (PLA-c/Talc 2), and 39.0\% (PLA-c/Talc-5), respectively (from bottom to top in Figure 4). This suggested that talc enhanced the crystallinity of PLA, while HA and shear decreased the crystallinity of PLA. The same phenomenon was also reported by Maria for lower HA content, but the high content of HA shows different trends [26]. Similar results could be observed in Figure 5 for PLAa/PLA-c blends, because more amorphous PLA limited the crystallization degree of PLA.

DMA is a powerful method to investigate the viscoelastic behavior of the PLA/fillers composites. In order to observe the viscoelastic behavior and glass transition of PLA, injection molded bars were subjected to dynamic mechanical analysis (DTA) in the range from $-50^{\circ} \mathrm{C}$ to $120^{\circ} \mathrm{C}$. The temperature curves of storage modulus and the loss factor are shown in Figure 6. It is shown that the storage modulus of the composites was greater than the pure PLA matrix, indicating the reinforcement effect from the inorganic particles. The storage modulus of all samples decreased with the increase in temperature with significant decrease in the range between 60 and $80^{\circ} \mathrm{C}$. Because of the significant increase of the chain mobility of PLA near the $T_{g}$ of PLA, the modulus reduced dramatically around $T_{g}$. Nevertheless, incorporating filler into PLA led to a longer plateau on the storage modulus than that of pure PLA, indicating the increase of the softening temperature in comparison to PLA alone. This implies that addition of inorganic filler could increase the thermal stability of the PLA matrix and the thermal stability further increased when the composite is crystallized.

The glass transition temperature $\left(T_{q}\right)$ could be derived from the curves of the modulus loss. Generally, $T_{g}$ is interpreted as the peak of the curve of the modulus loss obtained during dynamic mechanical analysis. The $T_{g}$ of the two PLA/filler composites shifted to higher temperature due to the presence of the inorganic particles within the PLA matrix. The shifting of $T_{g}$ to higher temperature could be attributed to the agglomeration of inorganic particles, which lowered the mobility of polymer chain. Therefore, more energy was required to mobilize the polymer chains, resulting in a higher $T_{g}[26]$. 


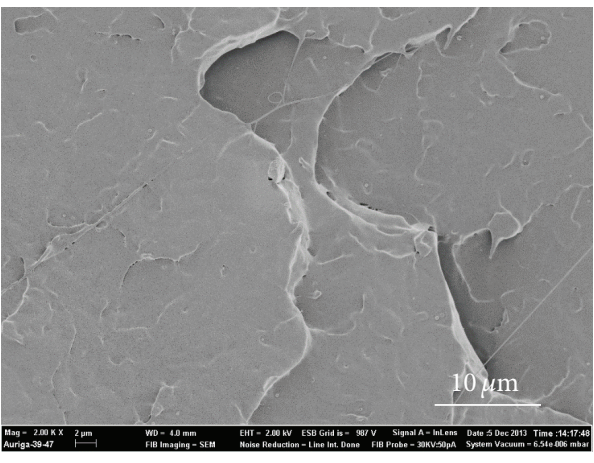

(a)

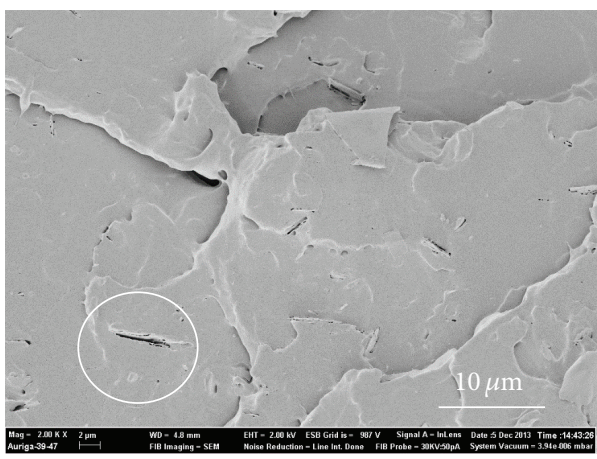

(c)

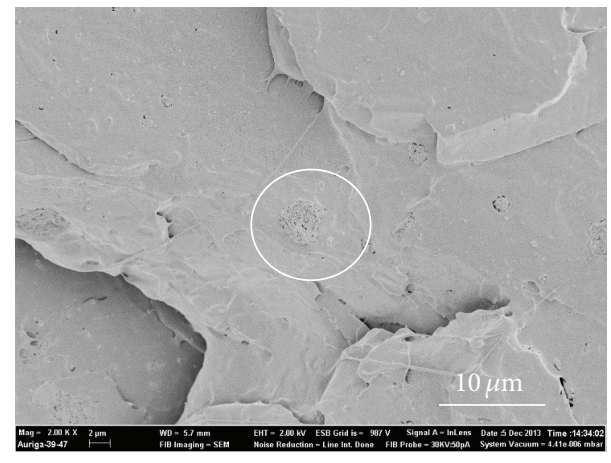

(b)

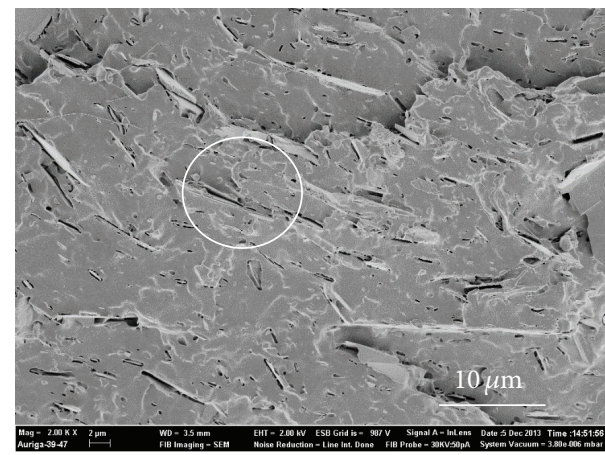

(d)

Figure 3: SEM images of PLA based composites: (a) PLA4032; (b) PLA-c/HA; (c) PLA-c/Talc 2; (d) PLA-c/Talc 5.

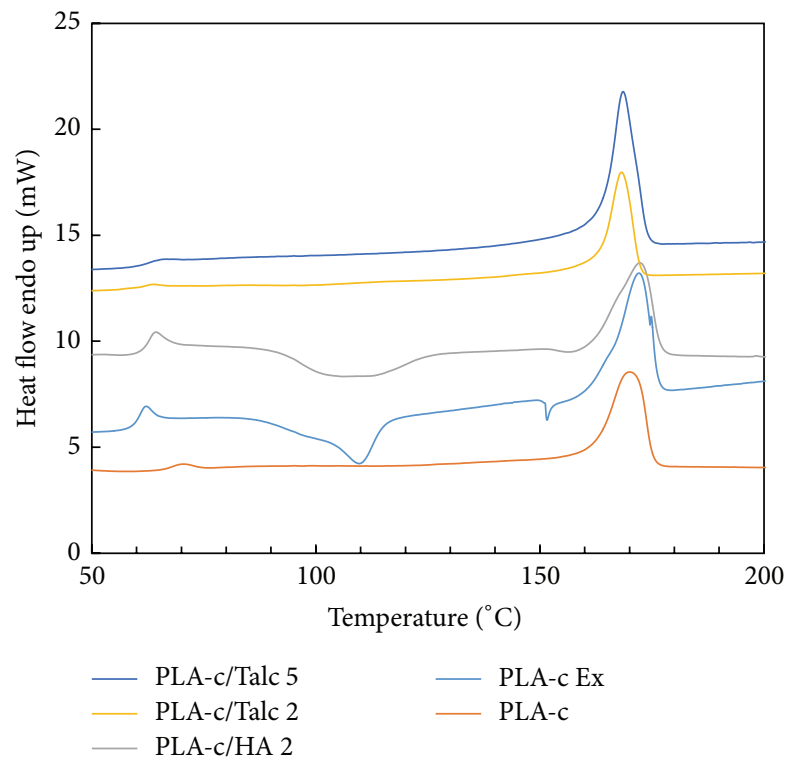

(a)

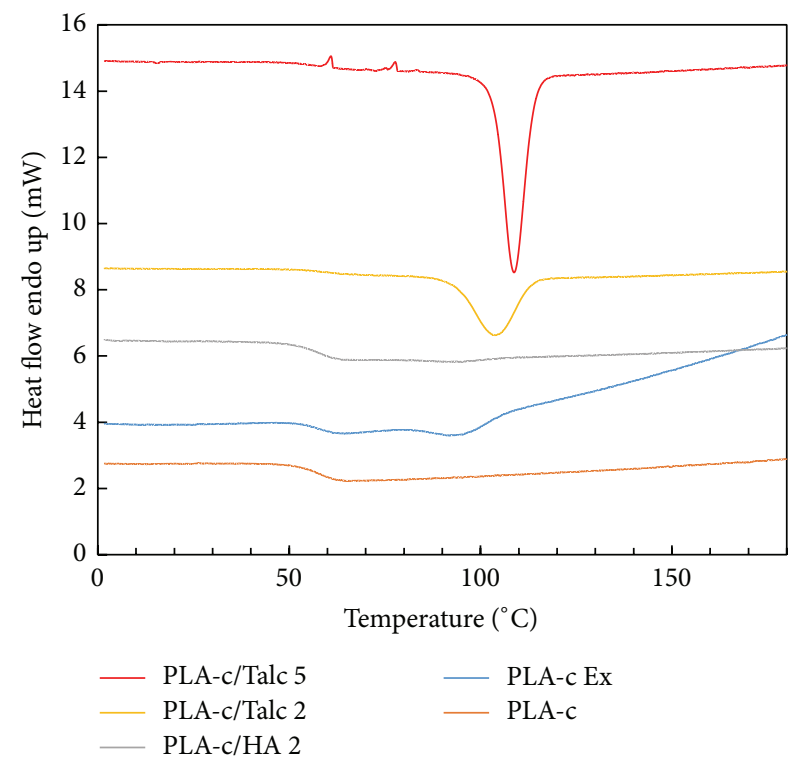

(b)

FIGURE 4: Effect of the weight percent of the filler on DSC result of heating (a) and cooling (b) of semicrystalline PLA (PLA-c).

3.3. Effect of Fillers on Mechanical Behavior of PLA/HA Composite. Figure 7 presents the tensile strength and elongation of the inorganic fillers effect on different PLA including semicrystalline PLA, amorphous PLA, and their blend. It is shown that the tensile strength of the semicrystalline PLA is greater than that of the amorphous PLA or their blend. This conclusion was expected since higher crystallinity usually leads to high tensile strength. Talc could enhance the crystallinity of PLA, but lack of interfacial adhesion between talc and PLA limited the tensile strength of PLA/talc composite. 


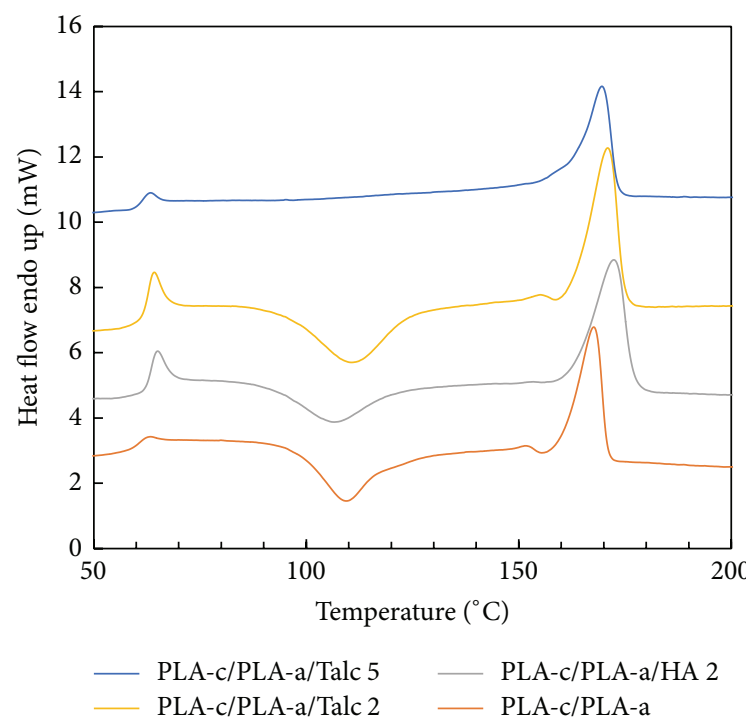

(a)

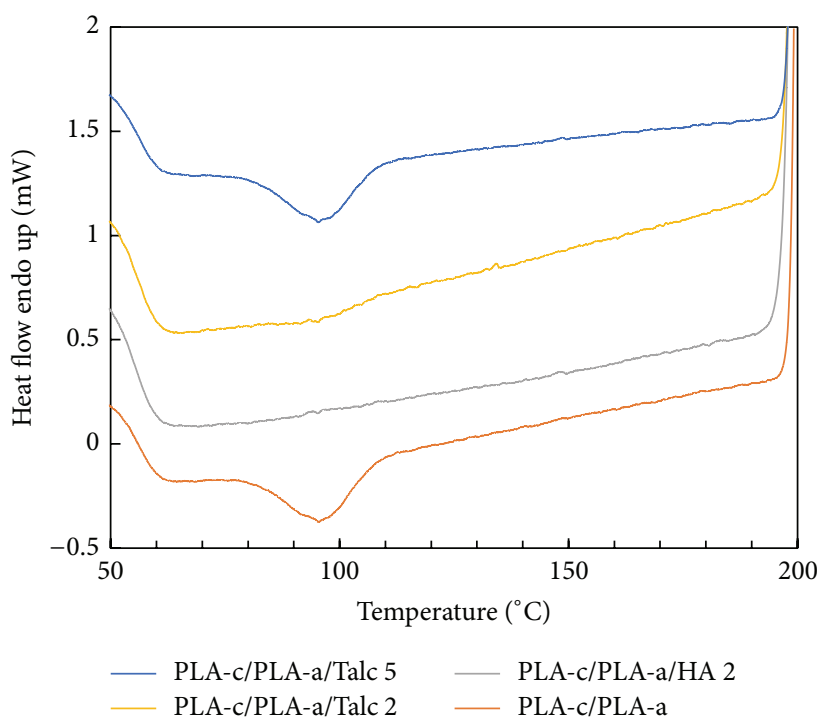

(b)

FIGURE 5: Effect of the weight percent of the filler on DSC result of heating (a) and cooling (b) of the blends of crystalline PLA and amorphous PLA (PLA-c/PLA-a).

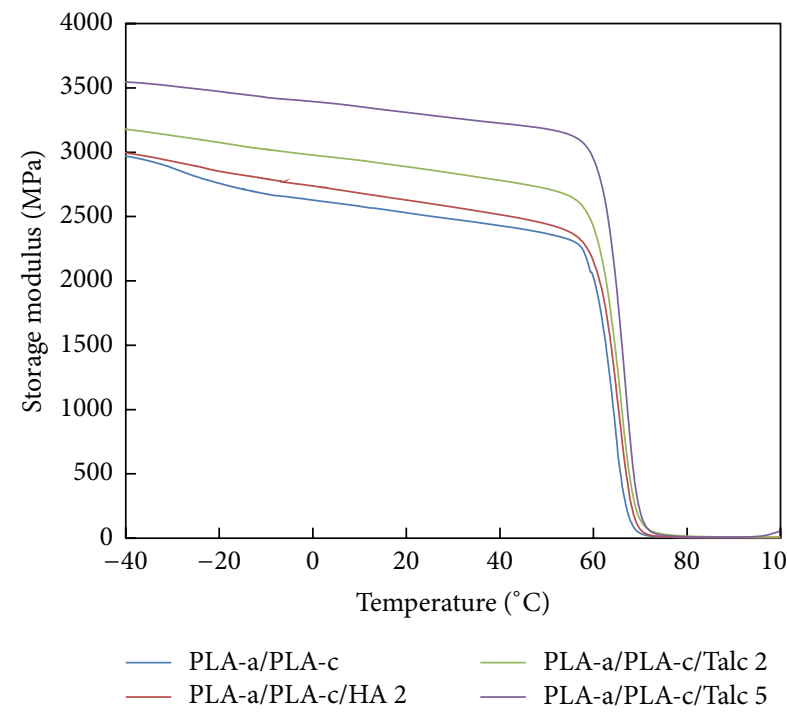

(a)

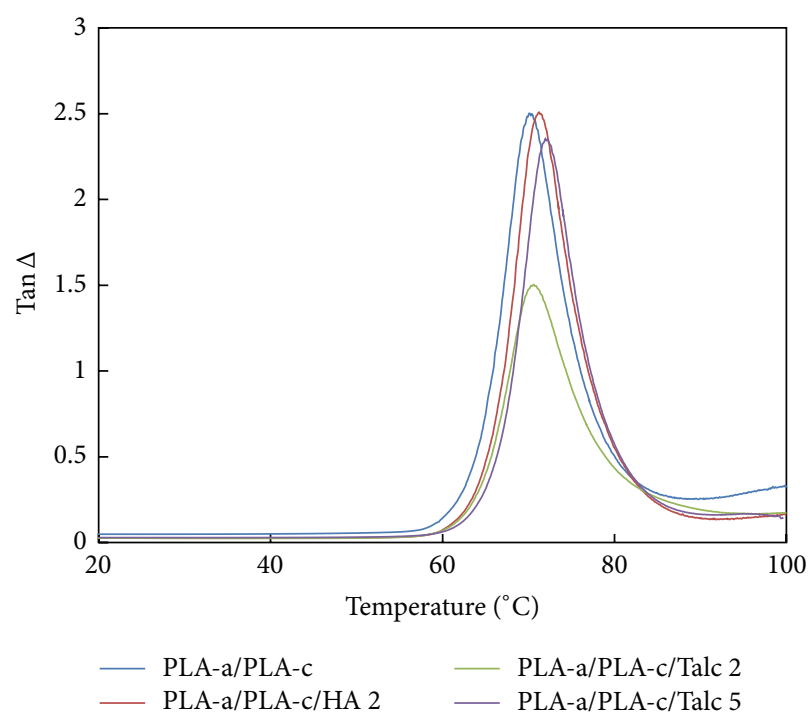

(b)

FIGURE 6: Effect of the weight percent of the filler on the storage modulus and Tan Delta of the blends of crystalline PLA and amorphous PLA (PLA-c/PLA-a).

Therefore, there was no obvious difference between PLA/HA and PLA/talc with the same loading level of the filler (2\%). This could be due to the lack of interfacial adhesion between the filler and PLA, which will be studied in the future. The enhancement of talc to the tensile strength of the amorphous PLA was shown in Figure 7. Previous results showed that talc could be used as the nuclear agent to enhance the tensile strength of PLA-based materials [21]. However, the melt compounding led to the decrease of molecular weight of PLA and weak interfacial properties. Figure 7 also shows that the elongation ratio of PLA was about 7\%. While it seemed that the amorphous PLA showed a less elongation, statistical analysis indicated that no significant difference was observed in semicrystalline PLA, amorphous PLA, or their blend.

The above results indicate that the mechanical properties of PLA depended on the molecular weight, crystallinity, and orientation. A number of strategies including melt compounding and filler type were investigated to balance the molecular weight, crystallinity, and orientation so that the mechanical strength can be improved. The high temperature 


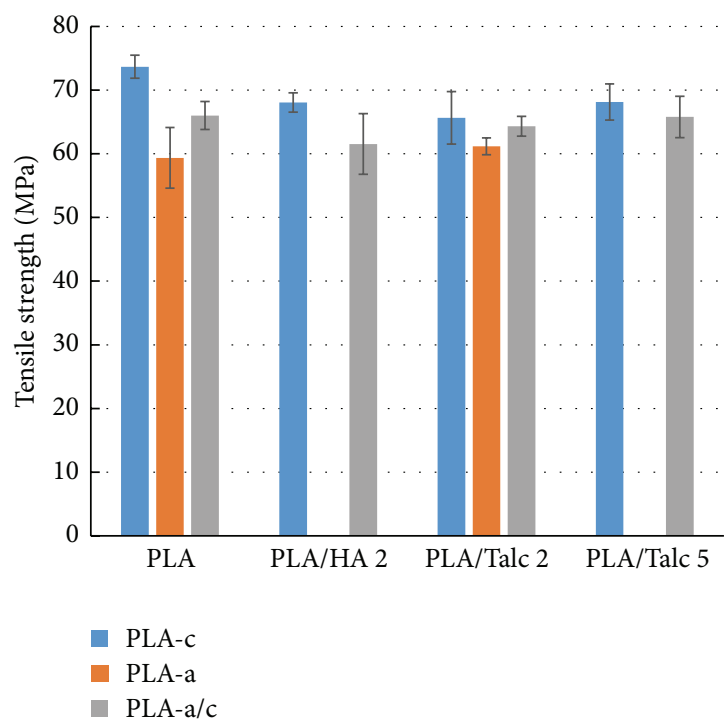

(a)

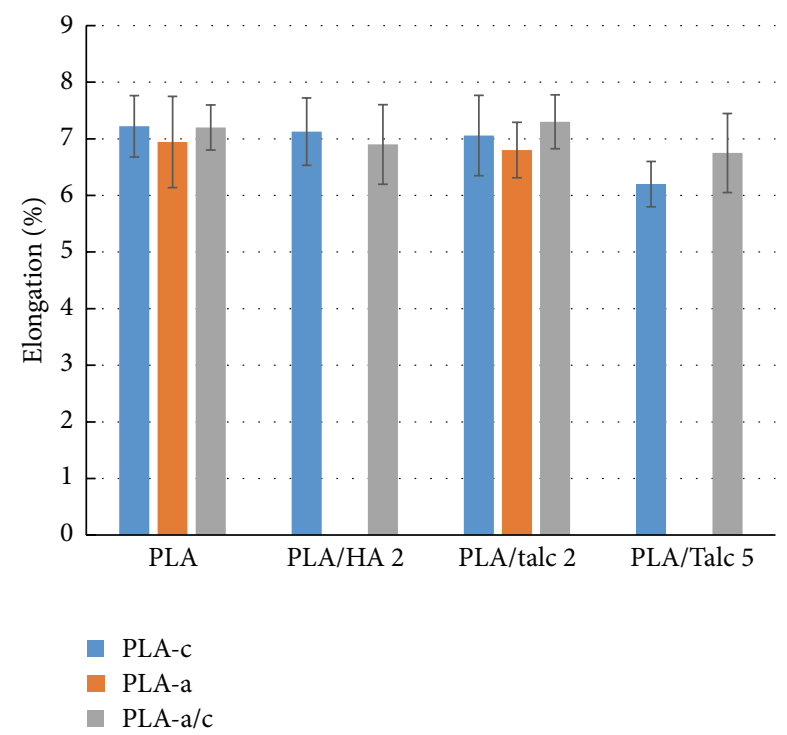

(b)

Figure 7: Effect of different inorganic fillers on the tensile strength and elongation of PLA.

from melt compounding could reduce the molecular weight of PLA. Inorganic particles such as talc could be used as nucleating agents to increase the crystallinity of PLA. However, the effect of HA as a nucleating agent was not observed. In the future, appropriate modification of HA surface in order to be used as alternative nucleating agent could be a potential way to improve the mechanical properties of PLA/HA composites.

\section{Conclusion}

The effects of talc and hydroxyapatite (HA) on the thermal and mechanical properties of two types of poly(lactic acid) (one amorphous and one semicrystalline) have been investigated. It is shown that the melting mixing made the inorganic filler distribute homogeneously in PLA matrix, which was confirmed by TGA and SEM. Nevertheless, GPC analysis indicated that the melting mixing could decrease the molecular weight of PLA, probably due to the shear, thus decreasing the mechanical strength. DSC analysis showed that talc increased, but HA decreased, the crystallinity of PLA. Mechanical tests indicated that both talc and HA increased the toughness of PLA; tensile strength depended on the crystallinity and the interfacial properties. Conclusively, this work suggested that melting condition and filler must be additionally optimized (such as surface modification of the filler) in order to improve the mechanical strength of the PLA composite.

\section{Conflict of Interests}

The authors declare that there is no conflict of interests regarding the publication of this paper.

\section{Acknowledgment}

This work was financially supported by National Institutes of Health (NIH/NIDCR/R01 DE021786).

\section{References}

[1] T. Wang, L. C. Chow, S. A. Frukhtbeyn et al., "Improve the strength of PLA/HA composite through the use of surface initiated polymerization and phosphonic acid coupling agent," Journal of Research of the National Institute of Standards and Technology, vol. 116, no. 5, pp. 785-796, 2011.

[2] H. Zhou, J. G. Lawrence, and S. B. Bhaduri, "Fabrication aspects of PLA-CaP/PLGA-CaP composites for orthopedic applications: a review," Acta Biomaterialia, vol. 8, no. 6, pp. 19992016, 2012.

[3] S. Sinha Ray, "Polylactide-based bionanocomposites: a promising class of hybrid materials," Accounts of Chemical Research, vol. 45, no. 10, pp. 1710-1720, 2012.

[4] E. Reverchon, P. Pisanti, and S. Cardea, "Nanostructured pllahydroxyapatite scaffolds produced by a supercritical assisted technique," Industrial and Engineering Chemistry Research, vol. 48, no. 11 , pp. 5310-5316, 2009.

[5] A. J. Wagoner Johnson and B. A. Herschler, "A review of the mechanical behavior of $\mathrm{CaP}$ and $\mathrm{CaP} /$ polymer composites for applications in bone replacement and repair," Acta Biomaterialia, vol. 7, no. 1, pp. 16-30, 2011.

[6] X. Zheng, S. Zhou, Y. Xiao, X. Yu, and B. Feng, "In situ preparation and characterization of a novel gelatin/poly(D,Llactide)/hydroxyapatite nanocomposite," Journal of Biomedical Materials Research B: Applied Biomaterials, vol. 91, no. 1, pp. 181190, 2009.

[7] E. Díaz, I. Sandonis, I. Puerto, and I. Ibáñez, "In vitro degradation of PLLA/nHA composite scaffolds," Polymer Engineering \& Science, 2013. 
[8] Y. Cui, Y. Liu, Y. Cui, X. Jing, P. Zhang, and X. Chen, "The nanocomposite scaffold of poly(lactide-co-glycolide) and hydroxyapatite surface-grafted with l-lactic acid oligomer for bone repair," Acta Biomaterialia, vol. 5, no. 7, pp. 2680-2692, 2009.

[9] J. Li, Y. Chen, A. F. T. Mak, R. S. Tuan, L. Li, and Y. Li, "A one-step method to fabricate PLLA scaffolds with deposition of bioactive hydroxyapatite and collagen using ice-based microporogens," Acta Biomaterialia, vol. 6, no. 6, pp. 2013-2019, 2010.

[10] J. Y. Liuyun, X. Chengdong, C. Dongliang, J. Lixin, and P. Xiubing, "Effect of n-HA with different surface-modified on the properties of n-HA/PLGA composite," Applied Surface Science, vol. 259, pp. 72-78, 2012.

[11] Z. Hong, X. Qiu, J. Sun, M. Deng, X. Chen, and X. Jing, “Grafting polymerization of L-lactide on the surface of hydroxyapatite nano-crystals," Polymer, vol. 45, no. 19, pp. 6699-6706, 2004.

[12] X. Song, F. Ling, and X. Chen, "Grafting polymerization of L-lactide on hydroxyapatite nanoparticles," Acta Polymerica Sinica, no. 1, pp. 95-101, 2013.

[13] L. Yu, H. Liu, F. Xie, L. Chen, and X. Li, "Effect of annealing and orientation on microstructures and mechanical properties of polylactic acid," Polymer Engineering \& Science, vol. 48, no. 4, pp. 634-641, 2008.

[14] X. Liu, L. Yu, K. Dean et al., "Improving melt strength of polylactic acid," International Polymer Processing, vol. 28, no. 1, pp. 64-71, 2013.

[15] C. Gao, H. Ma, X. Liu et al., "Effects of thermal treatment on the microstructure and thermal and mechanical properties of poly(lactic acid) fibers," Polymer Engineering \& Science, vol. 53, no. 5, pp. 976-981, 2013.

[16] H. Li and M. A. Huneault, "Effect of nucleation and plasticization on the crystallization of poly(lactic acid)," Polymer, vol. 48, no. 23, pp. 6855-6866, 2007.

[17] A. Shakoor and N. L. Thomas, "Talc as a nucleating agent and reinforcing filler in poly(lactic acid) composites," Polymer Engineering \& Science, vol. 54, no. 1, pp. 64-70, 2014.

[18] K. Madhavan Nampoothiri, N. R. Nair, and R. P. John, "An overview of the recent developments in polylactide (PLA) research," Bioresource Technology, vol. 101, no. 22, pp. 8493-8501, 2010.

[19] A. M. Harris and E. C. Lee, "Improving mechanical performance of injection molded PLA by controlling crystallinity," Journal of Applied Polymer Science, vol. 107, no. 4, pp. 2246-2255, 2008.

[20] H. Tsuji, H. Takai, and S. K. Saha, "Isothermal and nonisothermal crystallization behavior of poly(l-lactic acid): effects of stereocomplex as nucleating agent," Polymer, vol. 47, no. 11, pp. 3826-3837, 2006.

[21] F. Yu, T. Liu, X. Zhao, X. Yu, A. Lu, and J. Wang, "Effects of talc on the mechanical and thermal properties of polylactide," Journal of Applied Polymer Science, vol. 125, no. 2, pp. E99-E109, 2012.

[22] D. Qiao, W. Zou, X. Liu et al., "Starch modification using a twinroll mixer as a reactor," Starch-Stärke, vol. 64, no. 10, pp. 821$825,2012$.

[23] X. Liu, Y. Wang, L. Yu et al., "Thermal degradation and stability of starch under different processing conditions," Starch, vol. 65, no. 1-2, pp. 48-60, 2013.

[24] E. Petinakis, X. Liu, L. Yu et al., "Biodegradation and thermal decomposition of poly(lactic acid)-based materials reinforced by hydrophilic fillers," Polymer Degradation and Stability, vol. 95, no. 9, pp. 1704-1707, 2010.
[25] X. Liu, S. Khor, E. Petinakis et al., "Effects of hydrophilic fillers on the thermal degradation of poly(lactic acid)," Thermochimica Acta, vol. 509, no. 1-2, pp. 147-151, 2010.

[26] M. Persson, G. S. Lorite, S.-W. Cho, J. Tuukkanen, and M. Skrifvars, "Melt spinning of poly(lactic acid) and hydroxyapatite composite fibers: Influence of the filler content on the fiber properties," ACS Applied Materials \& Interfaces, vol. 5, no. 15, pp. 6864-6872, 2013. 

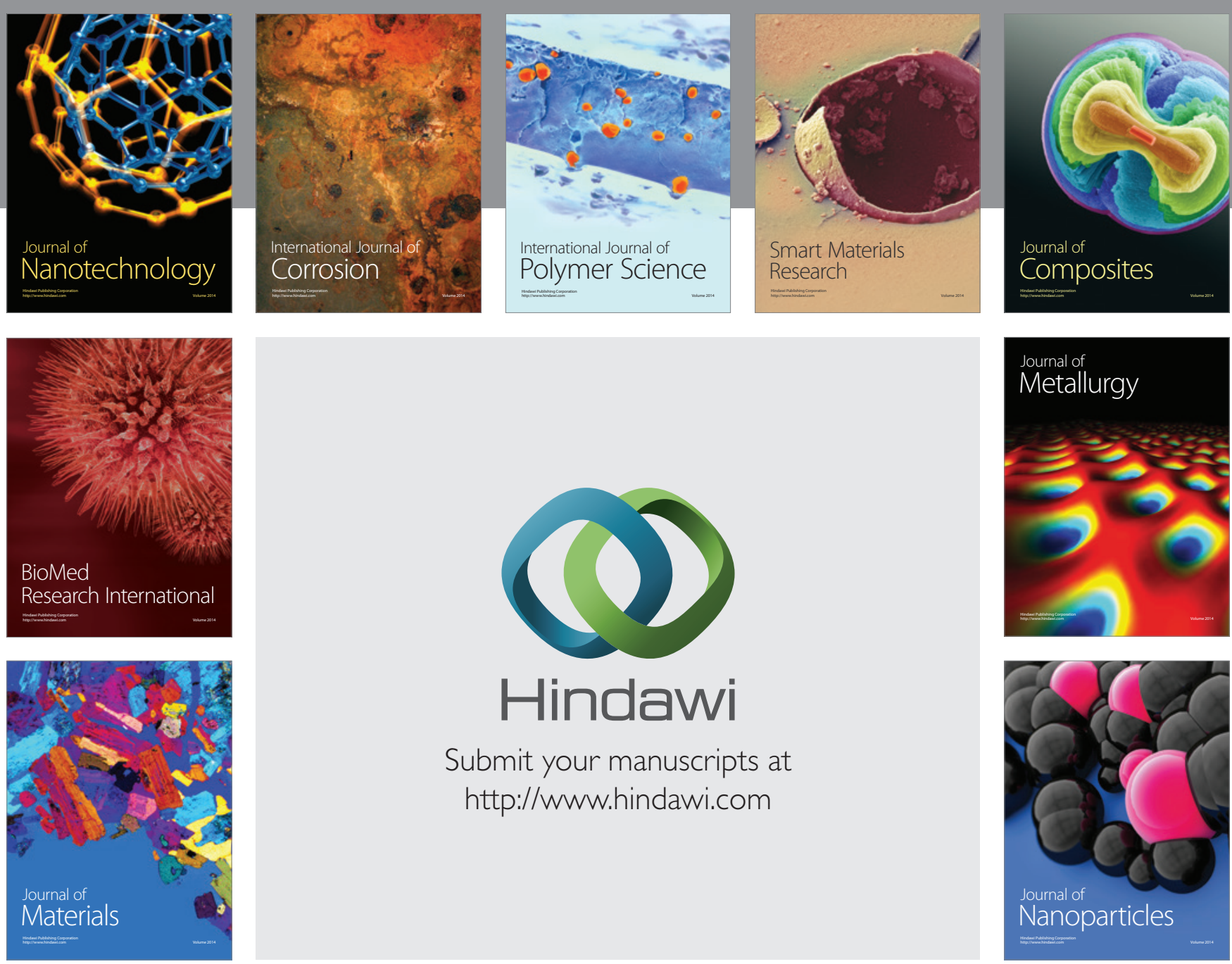

Submit your manuscripts at http://www.hindawi.com
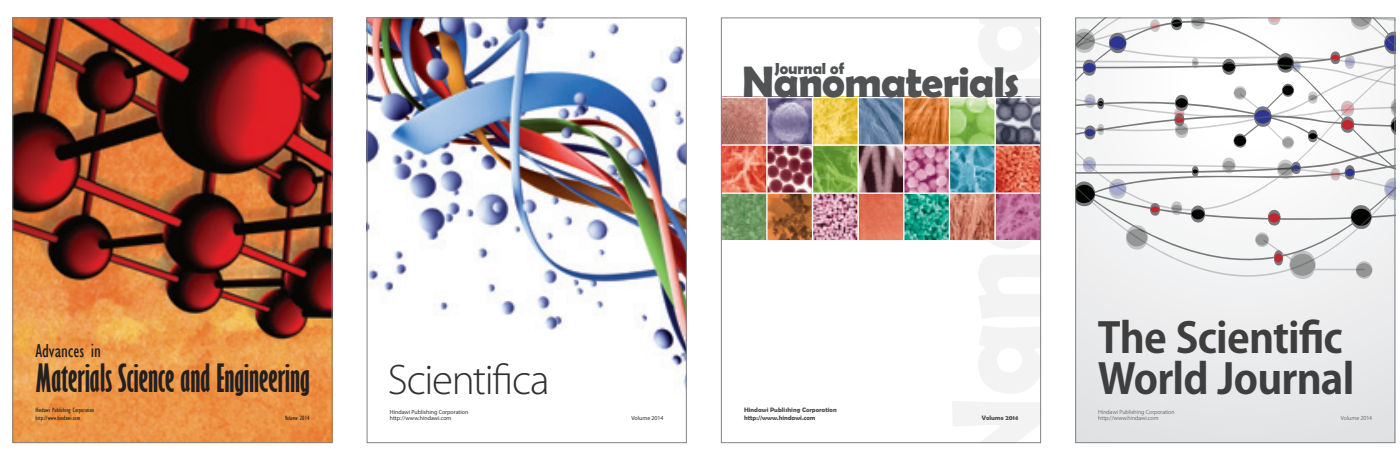

\section{The Scientific World Journal}
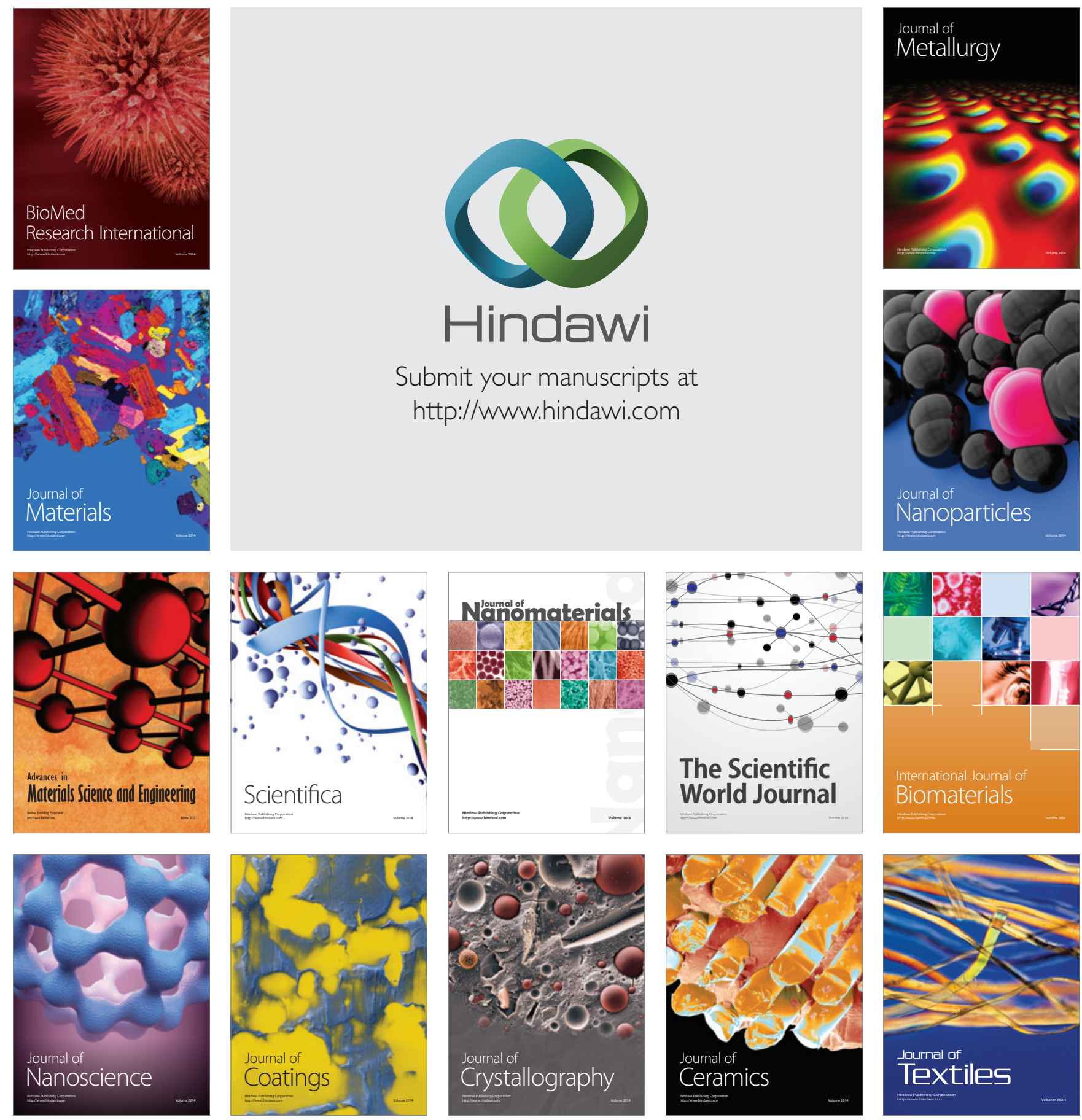